\title{
Family Names in Palestine: A Reflection of Culture and Life
}

\author{
Ahmad Atawneh \\ Hebron University
}

This paper investigates the sociolinguistics of the family names in Palestine. It hypothesizes that family names reflect the style of life in the past in terms of agriculture, professions, industry, human characteristics and place of living. The data were collected from the telephone directory published by the company of telecommunications in Palestine West Bank in 2001.All names having telephone lines are listed in the alphabetical order of the family names; 8,343 family names were found. One third of the sample are religious names which have forms similar to first given names like "Ali," "Hasan" and "abdul+any of God's names" like "abdul-Raheem" and "abdul-Rahmaan," or "Muhammad, Mahmoud and Ahmad." Such names do not reflect any aspect of social life. The other two-thirds of these names reflect lifestyle and human characteristics. Analysis was limited to this portion of names. The order of distribution from highest to lowest is: names denoting physical features, temperament, geography, agriculture, business, financial position, timing and planets.

To date, research has focused mainly on first names. (Kayed and Lance 2000) collected names of 141 individuals in Jordan. Tushyah, Lawson and Rishmawi (1989) surveyed 341 different Christian and Moslem names from the Ramla-Jaffa area. Abdel-Jawad (1985) collected 9000 male names and 4000 female names at Yarmouk University and studied the frequency of every first name for both genders. Giovanni (1982) classified the frequency of 830 personal names belonging to 830 telephone subscribers in the capital area of the Sultanate of Oman. Research on nicknames and family names is scant as evidenced by Tushyeh and Hamadallah (1992) who looked at 413 family nicknames in Palestine. As a side issue, Kayed and Lance (2002) looked into the family names of 141 individuals. Antoun (1968) studied nicknames in

Names 53:3 (September 2005):147-167

ISSN:0027-7738

Copyright 2005 by The American Name Society 
one village in the Jordan valley. His analysis covered nicknames expressing character, physical and personal traits, occupations, hostility, and place of origin. This paper looks into the sociolinguistic aspect of 8,343 family names in Palestine.

According to Whissell (2001), the meaning of a name does not come from sounds but rather from the association of the object, action, or concept described by the name. Similarly, Obeng $(1998,163)$ states that

"Names in Akana, as in other cultures, are pointers to their users' hopes, dreams and aspirations; they reflect geographical environment as well as fears, religious beliefs, and philosophy of life and death. Children's names may even provide insights into important cultural or socio-political events at the time of their birth."

The diversity of family names in Palestine reflects the kind of culture and life such families had in old times. According to Tushyeh (1992), surnames in Palestine originated in the eighteenth and the nineteenth centuries. Kayed and Lance (2002) found the family names in their sample dating back to 1850 . Family names reflect characteristics of people and their way of living in the environment. According to Antoun (1968), origin names, occupation names, and a few nicknames provide some ethnographic or historical information about the local culture.

A family name is seen as the identity of a person more than the given name. Upon knowing that somebody belongs to a family, an immediate positive or negative impression is made about that person depending on how his family is viewed in the society. However, there are meanings for family names that sound good and other meanings that sound ridiculous.

According to Dauzat (1949: 40) in 1539 a long-established custom was codified for assigning and preserving family names to pass down to succeeding generations. Family names 
had been based on a physical attribute, the place of residence, or the occupation of distant ancestors. Families often took the name of their villages, and in other rare cases, the villages took the name of their dominant families. According to Ruffie (1991), it has been noticed that the number of original family names began to shrink, and the richness of those diverse cultural origins is lost.

The closest study to the topic of this paper is that of Tushyeh and Hamadallah (1992) which investigated nicknames and family names in some Palestinian cities, villages and camps. Their sample was limited to 413 family names. In their analysis, they followed Antoun (1968) who classified family names in a village in the Jordan valley. The sample in this study is comprehensive $(8,343)$ including almost all family names in the West Bank and Gaza according to the Palestinian central department of statistics and the telecommunication department.

Though from a different culture, the study of Butkus (1999) is similar in the method of analysis to the mentioned studies. Butkus gave an outline and classification of Lithuanian nicknames. The current study is also similar in method to the mentioned studies. Therefore, the categorization here will be an adaptation to the ways used in former studies to suit the research purpose.

Family names must have been started as nicknames because many of the names refer to the outward appearance or characteristics of a person. Butkus (1999) classified the nicknames into ten categories with subcategories for each major category. The first observation made was that nicknaming is much more directed to males than females. This observation was supported in this study. Tushyeh and Hamadallah classified family names into 12 categories; while Antoun classified his sample into five categories.

Moyo (2002) investigated the aspects of nicknames in Tumbuka in South Africa and found that names showed a relationship with naming culture or subculture. He found that 
nicknames signify a class or privilege and status within a social organization. He also observed that nicknames were frequently descriptive and bestowed as a reflection of individual characteristics rather than hopes and desires of a person. Alford (1988) observed that nicknames usually differentiate or identify individuals more than do personal names.

Cross (2003) investigated Amish surnames and found that Amish surnames demonstrated the central role played by family groups in Amish settlement and migration.

Data Collection

The data were collected by going through the telephone directory, which was published by the Palestinian Communication Company in 2001 where names are listed according to the alphabetical order of family names. There are 8,343 family names. This sample is a comprehensive sample because having a telephone line for families only started after thirty years of occupation. Before the occupation in 1967, only few well-to-do families had telephone lines. The rest rushed to have lines in all towns and villages and every corner in the West Bank and Gaza. According to the records of the Telecommunication Company and the bureau of statistics in Palestine, all family names were included in the telephone directory of 2001.

Results and analysis

It has been found that 3205 family names are names, such as Ahmad, Ali, Hassan, etc., not related to environment or behavioral characteristics making up about one third (38\%) of the sample; 5174 names denote agriculture, industry, geography, physical and behavioral features, financial position, and timing making up about nearly two thirds (62\%) of the sample. Names denoting environment-related aspects will be the focus here, to give an idea about life and description of people in the past.

Table 1 shows the classification of the seven categories, including their frequency of occurrence. 
Table 1: Main categories of family names

\begin{tabular}{lll} 
Category & Frequency & Percentage \\
\hline Physical features & 1560 & $30.34 \%$ \\
Agriculture & 1478 & $28.70 \%$ \\
Temperament & 638 & $12.44 \%$ \\
Geographical area & 551 & $10.70 \%$ \\
Trade/industry & 528 & $10.32 \%$ \\
Financial conditions & 204 & $4.00 \%$ \\
Timing/Planets & 179 & $3.60 \%$ \\
Total & 5174 & $100.00 \%$
\end{tabular}

The largest category of names is of those that are based on physical features (see Table 2).

Table 2: Physical Features $(1560=30.34 \%)$

\begin{tabular}{cll} 
Categories & Frequency & Percentage \\
\hline Outward appearance & 714 & $45.8 \%$ \\
Organs/features & 211 & $29.6 \%$ \\
Size/Shape & 200 & $28.0 \%$ \\
Colors/numbers & 150 & $21.0 \%$ \\
Defective organs & 83 & $11.6 \%$ \\
Diminutives & 70 & $9.8 \%$ \\
Subtotal & 714 & $100 \%$ \\
Physiological & 332 & $21.2 \%$ \\
Voice-related & 245 & $16.4 \%$ \\
Motion/hands-legs & 196 & $12.6 \%$ \\
Physical peculiarities & 64 & $4.0 \%$ \\
Total & 1560 & $100 \%$
\end{tabular}

Physical features give a new identity to the named person, which is later handed down to the descendants as a family name. In this case, the feature is named and given to the named person. Usually first names are given at birth without knowing the future personal features of the child. First names 
are given in hope for a feature to be developed by the named person; while, nicknaming is given to a grown up after feature is developed. These names include mainly the features of size, shape, color and defective organs. Other features in this category are the physiological features including dexterity, sluggishness, strength, weakness and sickness. Pronunciation and speech difficulties are also represented in naming of this category. The following are some examples:

\section{Outward appearance}

\section{Color $(21 \%)$ and body organs $(29 \%)$}

Body organs make up 29\%; color makes up $21 \%$ of the sub-category. These two types make up 50\%. In terms of color, white, black and brown are found. Brown is called black asmar which is not as black as the color of Africans. Whitecolored people are outnumbered by other colors as expected in such geographical area with a climate which is neither hot to promote black color nor cold to promote white color. Examples of color are like mragtan "spotted skin," maswadi "of black," abu shagra "father of blond," alakhdar "the green," ahmaru "of red," Madhun "painted," loon "color," abu abyad "father of white," 'tum "darkness." As noticed by Tushyeh and Hamdallah (1992), a relatively large number of the family nicknames begin with the prefix $A b u-$, which means "father of." Therefore, the translation of examples will only include the meaning of the name without repeating the meaning of the prefix $A b u$.

In terms of body organs, all organs are used either in their metaphorical meaning or in their surface meaning marking the body by some irregular shape or quality. It is noticed that any of these features as a name goes with the prefix abu- "father" as seen in the following examples: $a b u$ Ein "eye," abu kaf "palm," abu ras "head," abu much "brain," abu jabeen "forehead," abu thra' "arm," abu thaan "ear," abu jadayil "locks," abu jild "skin." 


\section{Size and shape (28\%)}

Size and shape make $28 \%$ of the sample, which means that about one-third of naming here goes to shape and size of the body of a person as short, tall or square like. Features of beauty or ugliness are also found in names, like: beautiful, shining, fresh, dry, old skin and soft as seen in the following examples:

Naa'im "soft"

hirish "shabby"

abu shayib "grey head"

abu kbir "big"

abu Sharib "moustash"

abu jild "skin" marbou" "square like"

qasir "short"

makhul "of black eyelashes"

ghandur "red cheek"

abu daqin "chin"

abu hajib "eyebrow."

\section{Defective organs (11\%)}

Such names make up $11 \%$ of the sample. These names are given to mark defective organs, which do not seem to be liked by the named or the community. However, the community imposes this name on the person who seems to be in a weak position and unable to resist or deny this deficiency as seen in the following examples:

$\begin{array}{ll}\text { 'amya "blind" } & \text { kaseeh "crippled" } \\ \text { ?atrash "dumb" } & \text { 'ora, orani "one-eyed" } \\ \text { abu 'amsha "shaby lashes" } & \text { abu haweeli "cornered eye." }\end{array}$

\section{Diminutives (9.8\%)}

Such types of names are frequent in the sample with all sorts of attributes including body parts in this category. Some of them are metaphorical like those of Lithuanian nicknames, especially if the mind is small like uqeyl. Any other part may be small like stomach, back, finger, tooth and leg or even the whole body in saying about somebody whose size is small and last born in the family greyd l'ish "the small monkey of the nest." Other examples are seen in the following:

M'eywi "of small stomach" abu sneyni "small tooth" Abu thuheyr "small back" 
abu kreyshaan "small stomach" "uqeyl "small mind" abu bteyn "small stomach" bseys "small cat"
Abbu rjeyli "small leg" Abu sbayey' "finger" dweyk "small rooster" obeyd "small slave."

Physiological features(21.2\%): Sluggishness, strength, weakness, sickness

Strength is a favorable feature and therefore it is represented in naming showing power at sometimes as mansour "victor" and showing savageness as in khammash "biting," at other times. Weakness or sluggishness is another disliked feature that has been represented. Names of prevailing diseases at the time were also found including burns and liver disease or paralysis of some body organs as seen in the following examples:

looh "board like"

Abu 'aaqli "shyness"

mhaawish "fighter"

qateel "killed"

abu mtaawi" "obedient" libbaad "very slow"

abu haalmi "merciful" mathbuuh "slaughtered" Abu sharaar "sparks" abu heybi "feared" abu sam'aan "good listener" abu 'asab "nerve"
abu khammaash "skirmishing" abu sall "basket" kaseeh "crippled" abu mahrouq "burned" faluji "paralyzed" mshahwar "darkened" yaraqaan "hepatitis."

\section{Voice-related names $(16.4 \%)$}

Voice names are representative of natural voices coming from kinds of birds or other animals. Some names are difficult to explain or associate with any known voice. Some defective pronunciation may result in naming somebody after that kind of voice.

Examples of such names are as follows:

naa'uq "crow's voice" abu saawi "chickens' voice" taqtuq "cracking" qaaq "Hen's voice"

abu qweyk "bird's voice"

abu sayyah "crying" 
karkar "series of laughs" abu na' ur "falling water"

fahhah "making snake voice" zaghrut "happy sound" tarbaaq "hitting sound" wannan "cat-like voice"

\section{Body Motion (12.6\%)}

This type of names shows the kind of motions a person may have including liked or disliked motions like fast going, courageous, or lame like and uncontrolled as seen in the following examples:

Abu 'arja "lame"

'anfuus "uncontrolled"

abu mayyali "bending"

mighwar "courageous" abu ja'as "pride"

abu dahrouj "stone-like moving," 'ajuoli "quickening"

masaar'e "fast going."

\section{Physical peculiarities (4\%)}

Physical peculiarities are always found in people; and some of these peculiarities are picked by the community to mark a person and given as a nickname which later becomes a family name as seen in the following peculiar physical associations:

Khraawat "shit-like"

khasees "mean'

da'our "penetrating"

sarmi "old shoes"

tazaz'a "funny"

The second highest category is agriculture-related names marking a very important aspect of life in the history of Palestinians.

Agriculture - Farming names (28.7\%)

Throughout history, it has been known that Palestinians live on farming. That is why many of the family names associate with names of crops. In particular, the names that begin with $a b u$ 'father of' have most of such farming names. Palestine is usually called the land of 'milk and honey' the production of which needs plants and flowers for animals 
to live on. Palestine is also a holy land as mentioned in the Bible and the holy Koran. Some plants and animals are mentioned in the Koran, i.e., teen "figs," zaytoon "olives," rumman "pomegranate," nakhl "palms," 'inab "grapes," basal "onion," thuum "garlic." All these have been used as family names. There are too many other plants that are grown in Palestine, and used as family names, to mention a few: adas "lentils," foul "broad beans," hummus "chickpeas" and Za'tar "thyme." Such beans and seeds in general and olive oil and thyme in particular, make popular meals for many people.

As for animals and birds, some of them are mentioned in the Koran like baqar "cows," khayl "horses," hameer "donkeys," bighaal "mules," an'aam "cattle," kabsh "ram," na'ja "ewe," jamal "camel," naaqa "female camel," huut "fish," hudhud "peacock," naml "ants," hayya "snake," ghuraab "crow."

As seen in the table above, names designating agriculture make up a high percentage (18\%). This supports the hypotheses.

Table 3: Agricultural names (28.7\%)

\begin{tabular}{llll} 
Category & frequency & percentage \\
\hline Animal & 590 & $40 \%$ \\
& domestic & 224 & $37.97 \%$ \\
& wild & 177 & $30.00 \%$ \\
& birds & 100 & $17.00 \%$ \\
& insects & 67 & $11.40 \%$ \\
& diminutives & 22 & $3.73 \%$ \\
\hline \multirow{4}{*}{ Plants } & subtotal & 590 & $100 \%$ \\
& & 327 & $22 \%$ \\
& vegetables & 115 & $35.00 \%$ \\
& herbs & 82 & $25.00 \%$ \\
& fruits & 70 & $22.00 \%$ \\
& beans & 44 & $13.00 \%$ \\
& diminutive & 16 & $5.00 \%$ \\
& subtotal & 327 & $100 \%$ \\
Others & & 561 & $38 \%$ \\
\hline Total & & 1478 & $100 \%$
\end{tabular}


Table 3 shows the breakdown of this category.

\section{Names of animals as family names}

Names of animals (40\%) make the highest percentage among the agriculture-related names. This is an indication of the way of life in Palestine in $18^{\text {th }}$ and $19^{\text {th }}$ century. Of all animals, tame animals are $(37.75 \%)$. This fact shows that agriculture depended a lot on domestic animals. Such animals were and still used for food, plowing, riding and clothes. Of such animals are: cows, camels, lambs, sheep, horses, donkeys, cats, puppies, rams, and dogs. Among birds are: doves, hens, checks, roosters, ducks, and turkeys.

Names of wild animals make up (47.16\%). This category gives an idea about the kind of wildlife in Palestine. Some of such animals, were hunted for food, others were predators and reptiles. Examples of such names are like: asad "lion," feel "elephant," sahliyyah "lizard," thubbani "fly," sa'dan "monkey," nimir "tiger," hayya "snake," aqrab "scorpion," jundub "grasshopper," bargouth "flee," nahli "bee," faraash "butterflies."

If the country did not have animals like elephants, then people must have heard about it from stories. Insects are also listed under wild animals. They are listed as one group indicating the kind of insects or bugs in Palestine. Insect names in this category are either same as the name of the insect or their derivations, such as: abu jaraadi "female locust," abu namous "mosquito," abu fasfus "diminutive of gnats."

Diminutives of animals are very common as well as diminutives of other things. Such names are like:

kleyb "small dog"

jhayshi "small ass"

fheyd "small leopard"

dweyk "small rooster"

sways "small checken." $n u^{\prime} a y z$ "small goat"

bseys, qteyt "small cat"

breygheeth "small flee"

thweyb "small wolf" 
Such naming may have resulted from nicknaming young children in ways of fun that derived from the environment. This diminutive type is observed in almost every category of names. But this type of diminutive animals is the most prevalent among other types.

\section{Names of plants as family names}

There are 322 plant names making up $20 \%$ of the agriculture names. As it is the case with animals, one may study the kind of plants that grow in Palestine from their names. It is noticed that concern in plants is mostly geared towards vegetables, fruit trees, herbs and beans. Such plants are necessary for life in terms of food. Other plants like wild plants or forestry plants were the least observed. This type of naming also means that the land of Palestine is fertile and can be depended on for growing such plants. Most vegetables are not irrigated because the area lacks rivers and springs. The following are examples:

Qanabeyta "cauliflower" qar' "pumpkin" jazar "carrots" basal "onions"

Karaz "cherries"

batteekh "watermelon"

njaas "pears"

thura "maize"

inabawi "of grapes"

looz "almonds"

abu balah "of dates"

abu ruz "of rice"

abu snober "of pines"

abu sh'iir "of barley"

abu za'rur "of azarolus"

kusa "marrows"
zaytoon "olives"
bamya "okra"
inab "grapes,"
abut teen "figs"
tuffaha "apple"
hummus "check peas"
liftawi "turnip"
qamhaawi "of wheat"
fuul "broad beans"
abu lfilfil "of pepper"
abu ladas "of lentils"
abu thoom "of garlic"
abu l'jeen "of dough'
leymoon "lemons"

Diminutives are of low occurrence $(5 \%)$ here because of their negative associations. Examples of this type are: $a b u$ 
'sheybi (father of a weed), abu qrey' (father of small pumpkin), $a b \dot{u} z u^{\prime} y s t i r$ (father of small thyme), fleyfil (small pepper), ghuseyn (small branch), Bseyli (small onion), shweyki (small prick). It is also noticed that many of these names are related to agricultural products.

\section{Temperament (12.34\%)}

All kinds of temperaments are represented. Among these are names of loving people or showing a state of happy life; other types are those of unhappiness or misbehavior like being rude or obstinate as seen in the following examples:

Mhalwis "disturbed"

$n a a^{\prime} s i$ "sleepy"

asabiyyat "nervous"

mahbuub "loved"

ghadbaan "angry"

mssa'id "helpful"

mansi "forgotten"

$a b s i$ "frowining"

abu mas'uud "lucky"

abu safi "of clear"

abu sakraan "drunk." mwaswis "doubtful"

kathim "secretive"

aneed "obstinate"

mhashshish "drunk"

farhaan "happy"

msarsa" "worried"

muhtadi "guided"

abu keyfi "of happiness"

abu Hazeen "of sad"

abu samhaan "forgiving"

Geographical area (10.7\%)

Names of geographical areas clearly show the places from which many families in Palestine emigrated. Countries in the region are represented by the name of the city or country or both like: Egypt, Turkey, Iraq, Syria, Lebanon, Yemen, Jordan, Qatar, and even Italy, India, Cyprus, the Sudan, and Malta. Some countries are far away from Palestine and therefore, it could be that through the history of wars some people came to settle down in Palestine taking names connecting them to their original countries.

The break down of this major category is as follows: 


\begin{tabular}{llll} 
& Frequency & percentage \\
\cline { 3 - 3 } 1. Place where they came from & 260 & 47.20 \\
2. Popular place & 156 & 28.30 \\
3. Place of settlement & $\underline{135}$ & 24.50 \\
& Total & 551 & 100.00
\end{tabular}

The highest percentage of these components in naming is that of the places where people came from. This percentage seems logical because usually such names are likely to be associated with the places from which they emigrate like those known in the US as having Indian-American, Arab-American, SpanishAmerican, etc. The following are examples of such names:

\begin{tabular}{|c|c|c|}
\hline East & Qatari "of Qatar" & Karaki "of Karak" \\
\hline & Salti "of Sult" & Irani "Iranian" \\
\hline & 'iraqi "Iraqi" & 'ajlouni \\
\hline & Hindawi "Indian" & \\
\hline$\underline{\text { West }}$ & Malti "Maltese" & qubrusi "of Cyprus" \\
\hline & masri "Egyptian" & qubti "Coptic" \\
\hline North & shami "of Damascus" & Suri "Syrian" \\
\hline & Turki "Turkish" & stanbuli "of Istanbul" \\
\hline & abu aasia "of Asia" & Kurdi "Kurdish" \\
\hline & Afghani "Afghani" & \\
\hline Sou & Yamani "Yamanite" & Sudani "Sudanese" \\
\hline & Makki "Meccar & \\
\hline
\end{tabular}

\section{Names of local residence (cities, villages)}

Names in this category are common in different cultures. People may carry the name of a local residence whether it is a town or a village or even popular places in the area. In particular, when somebody moves from his original town to live in a new place where he is easily identified by his original town. Usually of the suffixes "-awi/-ani/-i" is added to the name of the town of village. Such examples are given in the following list:

Nabulsi"Nablus"

Naasiri "Nazareth"

Naquri "of Naqura"

majdalawi "of Majdal" 
Qalqili "of Qalqilia" Qudsi "of Jerusalem"

Ajjouri "of Ajjour" Asqalani "of Ashkilon"

Akkawi "of Accra" Anabtawi "of Anabta"

Gazzawi "Gazzan" Ghawarni "of Gour"

Hefawi "of Haifa" Ramlawi "of Ramli"

Salfiti "of Salfit" Liddawi "of Lud"

Trade and industry $(10.32 \%)$

To have a full picture of life, one has to know the kinds of professions and trades available at the time of giving such names. The following is the distribution of the types of names in this category:

Table 4: Trade and Industry names

\begin{tabular}{lll} 
Type & frequency & percentage \\
Instruments & 186 & 35.30 \\
Industry & 129 & 24.40 \\
Trade & 44 & 9.30 \\
Education & 111 & 21.00 \\
CriminalProfessions & 53 & 10.00 \\
Total & 528 & 100.00 \\
\hline
\end{tabular}

There is a big discrepancy between the rate of this category $(10.32 \%)$ and the category of agriculture $(28.7 \%)$. That is to say the society was, at the time, much more of agricultural than industrial. The means of industry were not available; there was no petrol, no skilled labor, and no money to build factories. However, this group is important because by means of such names we could tell the kind of primitive industry available like carpentry, copper works, weaving and sewing; there are also food related businesses like baking, making spices, and pastry, salt-making. Examples of such names are given below:

Qazzaz "Silk man" qattan "Cotton man"

Fakhuri "Pottery man"

Fahhaam "coal man'

Lahhaam "butcher"

Fallaah "peasant" 
162 • NAMES 53:3 (September 2005)

Farraan "Oven man"

Tahhaan "Milling man"

'assar "Juice man" 'attaar "spices man"

Qassaab "butcher"

Najjaar "carpenter"

Looking at these names, it seems obvious that such represented professions are the kind needed for simple life. There is no sophistication observed in these professions. They are either food-related professions or other types that would help in making clothes or services necessary for simple industry.

There are other names for professions related to toughness or power related actions as follows:

Abu 'asaakir "father of troops" haddar "like thunder"

mhaarib "fighter"

hawwaash "Attacker"

Abu d'eys "father of crushing"

shunnaq "hanger"

thabbah "slaughterer"
Abu jirmi "father of crime"

katalu "killer"

najajri "clipper"

mhaarib "fighter"

hreybaat "small fighters."

Other names denoting clerical and educational professions are also represented showing the kind of jobs people had at the time. Such examples are:

Mushrif "supervisor"

mufti "advisor"

wazeer "minister"

kaatbi "clerk"

falaki "astronomer"

turjuman "translator" mu'allim "teacher"

naathir "principal"

qaadi "judge"

faqih "scholar"

A'fandi "well-dressed"

rasmi "official"

Other names close to this field are those that show instruments as the owner of something that has become a nickname to the person, which later became the family name as seen in the following:

Qaddaha "lighter"

qa'qur "jar" qadah "cup"

Gharabli "filter man" 
famous "lantern"

abu dalu "father of pail"

$a b u$ Khusa "father of knife"

abu hasiri "father of mattress"

$a b u$ kheyt "father of thread"

abu jazmi "father of shoe"

abu munshaar "father of saw"

abu qumsaan "father of shirts" abu farwi "father of fur"

abu ghalyun "father of pipe" abu seif "father of sowrd"

Financial conditions (4\%)

Under this category, we have two kinds of names, those related to richness $(174 ; 85 \%)$, and those related to poorness $(30 ; 14.7 \%)$. It seems obvious from the percentages that the majority of names in this category go under richness $(85.3 \%)$ rather than poorness $(14.7 \%)$. This could be an indication that people are more attracted to richness or hope that naming might bring luck to the named. Palestine in history was a junction for connecting the North (Syria) with the South (Egypt) and East (Jordan, Iraq) with the West; that situation may have benefited residents in terms of economy. Nowadays, Palestine is not one of the rich nations. Rich names show possessing expensive metals like gold and sliver, or show the pride of being rich and respected. However, poor names show the bitterness of poverty and indications of kind of poor dressing or hunger and needy people. Examples of richness names are in the following list:

Taaj "crown"

thahab "gold jalaali "majestic"

thurayya "star"

fadda "silver"

$a b u$ ddahab "father of gold"

Lulu "oister"

marzuq "provided" baasha "Pasha"

Alsharif "honorable"

Khazni "safe"

Zumurrud "precious stone'

$A b u$ johar "father of jewels"

Aziz "of pride" 
Examples of poverty are given in the following list:

Faqir "poor"

Mahruum "deprived"

Ghbaar "dust" qanou' "satisfied"

abu ssabir "father of patience" $a b u$ zuhdi "father of enough"

Abu murraar "father of bitterness"

Adam "nothing"

Saq'aan "feeling cold"

Shahatit "beggars"

Haffi "bare footed"

Kasaayir "losses"

yutum "orphanage"
shhaati "begging"
jee'aan "hungry"
shreytih "dressed in rags"
ja'uuni "hungry"

yutum "orphanage"

Time and heavenly bodies (3.5\%)

Most of these names belong to days $(93 ; 51.6 \%)$ which occur in life more frequently than other types. The next highest is stars $(47 ; 26.6 \%)$, the lowest are months $(25 ; 14 \%)$ and seasons $(14 ; \%)$. Such names either mark the time of birth for some one, or given for religious reasons as such times were seen as blessed times.

Examples of day-related names are given in the following list: abu sabt "Saturday," abu jum'a "Friday," abu khamees "Thursday," abu leyl "night," subuh "morning," abu bukra "tomorrow," abu 'arafi "arafi day," 'aashur "tenth day" abu Eid "festival."

Examples of month names are like Rajab (Rajab), Ramadan "Ramadan," shbaat "February," abu sha'baan "Sha'baan," abu mharram "Muharram," nisaan "April." Examples of seasons are like abu rabee' "Spring," Seyf "Summer," Shita "Winter," Taqs "weather," haraara "heat." Examples of stars are njuum "stars," hlaal "moon," abu shams "sun," abu shhaab "meteorite," abu shamsiyyi "umbrella," abu nijmi "star," abu badir "Moon," thrayya "star," qumraan "Moons."

The diminutives are funny names rejected by today's standards. They must have been given for ridiculing the related person or family. Examples of such names are like qeymari "small moon," abu shmeys "small sun," abu njeym 
Family Names in Palestine • 165

"small star," abu hleyyil "small moon," morning," abu sbetaan "small Saturday."

abu sbeyha "small

\section{Other names $(\mathbf{3 8 \%})$}

This category is one-third of the sample. Such naming is expected since name givers like to keep track of ancestors and hand it down to later generations. There is some pride in such a way, especially, if it has religious background or famous characters. Examples of these names are not translatable because they are proper names of persons usually of religious history. Religious names could be single or compound. Compounding happens because people like to have the blessing of God if the first compound name is a name of a prophet or one of God's 99 names. Such names include abudul plus one of God's names, like: abdul Kareem, abdul rahman, abdul raheem. This high percentage of names in the sample shows the effect of Islam and Christianity on naming. In this regard there is little to say about such names except the fact that they indicate the kind of religions people at the time. None of the names is a common Jewish name. Proper names but non-religious have such examples as: Bataarsi, "of Peter," Tamimi "After Tamim," one of the prophet's companions" Ansaari "one of the Medina supports of Mohammad," $a b u$ Hasan, abu Hammad, abu khalaf, abu Amir, abu Talib, abu Rashid, Atawneh, Atwan,

\section{Conclusion}

Family names in Palestine reflect aspects of human life in old times. These aspects include the physical features of people in terms of color, size and shape. Their features of behavior in terms of being generous, stingy or daring person besides other things are also reflected. Body motions in relation to being fast or slow are also represented besides the voice related features in terms of soft or harsh or squeaky. The other interesting finding is that of the kind of agriculture found at the time of giving family names. The naming reflects all kinds of agriculture including animals and plants that were found in the area with it's climate and geography allowing 
such living things to survive and be used by humans. To make the picture complete, the side of industry is also explored through naming. Therefore, we have a host of simple industry types and professions showing the non-sophisticated tools used at the time. Most of industry businesses were oriented towards food and clothing.

\section{References}

Abd-el-Jawad, Hassan. 1986. "Linguistic and Sociocultural Study of Personal Names in Jordan." Anthropological Linguistics 28, 80-94.

Alford, Richard D. 1988. Naming Identity; A Cross-cultural Study of Personal Naming Practices. New Haven, CT: Human Relations Area Files.

Antoun, Richard T. 1968. "On the significance of names in an Arab village." Ethnology,7, 158-170.

Butkus, Alvydas. 1999. "An Outline and Classification of Lithuanian Nicknames." In Names 47-2: 125-138, The American Name Society

Cross, John A. 2003. "Amish Surnames, Settlement Patterns, and Migration." In Names 51.3\&4(September \& December 2003): 193-214, The American Name Society

Dauzat, Albert. 1994. Dictionnaire etymologique des noms de famille et prenoms de France. Paris: Larousse.

Kayed, Issam, \& Lance,Donald M. 2002. "Personal names in Palestine and Jordan," 1850-1996. Onama,36,25-48.

Moyo, Themba. 2002. "Aspects of Nicknames Among the Tumbuka." In Names 50.3 (September 2002): 191-200. The American Name Society.

Obeng, Samuel Gyasi. 1998. Akan Death-Prevention Names: A Pragmatic and Structural Analysis. In Names 46.3 (163-187). The American Names Society. 
Oman, Giovani. 1980a. "Personal names in the Southern Region (Zurar) of the Sultanate of Oman." Oriente Moderno,60, 180-195.

1982b. Personal names in the capital area of the Sultanate of Oman. In Jacqueline Sublet (Responsible), Cahiers d'onomastique Arab 1981 (PP.95-113). Paris: Centre National de la Recherche Scientifique.

Ruffie, Jacques. 1991. La Fuite des patronymes. Le Monde. 3 July: 4 Saussure, Ferdinad de. 1983. Course in General Linguistics. (Translation. Roy Harris).London:

Duckworth.

Tushyeh, Hanna Y., Lawson, Edwin D.,\& Rishmawi, George. 1989. "Palestinian first names: An Introduction." Names,37, 245-264.

Tushyeh, Hanna Y., \&Hamdallah, Rami W. 1992. "Palestinian surnames derived from nicknames." Names, 40, 237252.

Whisell, Cynthia. 2001. "Sound and Emotion in Given Names." In Names 49.2 (June 2001)97-120. The American Name Society. 